\title{
EDITORIAL
}

\section{The ten wishes and hopes of the deputy editors of Intensive Care Medicine}

\author{
Giuseppe Citerio ${ }^{1 *} \mathbb{D}$, Anders Perner ${ }^{2}$ and Jean-Francois Timsit 3,4
}

๑ 2016 Springer-Verlag Berlin Heidelberg and ESICM

The number of submissions to Intensive Care Medicine (ICM) has increased continually to the point where we now reject more than $80 \%$ of the manuscripts submitted. The ICM editors do their best to select for publication those articles that are the absolute best because they:

1. Have a clinical message that changes the practice of ICU clinicians caring for patients at the bedside,

2. Add significantly to existing knowledge,

3. Are properly registered and comply fully with the relevant regulations,

4. Have a study design and methodology that enable authors to draw valid conclusions (i.e. minimal or no risk of bias).

Editors and authors are sometimes perceived as opponents confronting each other over a barricade. In reality, however, they share the same ambitions, i.e. to enhance the quality of the published articles and to produce day by day a better journal. Their common goals also include improvements in knowledge transfer, patients' outcomes and the quality of specialty journals.

We would like to share with you in this editorial the most important points that are taken into account when considering manuscripts for publication in ICM (Table 1).

- Intensive Care Medicine has the ambition to publish original, up-to-date articles reporting clinical research conducted to the highest possible ethical and methodological standards. Articles that add little to existing knowledge and those based on previously published datasets without adding significant infor-

\footnotetext{
*Correspondence: giuseppe.citerio@unimib.it

1 School of Medicine and Surgery, University of Milan-Bicocca, Via Cadore 48, 20900 Monza, Italy
}

Full author information is available at the end of the article mation do not meet our expectations and will hardly be in a position to compete with other manuscripts submitted to the journal.

- With our younger colleagues in mind, we strive to provide high-quality educational materials [1] with clear tables, didactic figures with judicious use of colour, and clear flowcharts [2] that are easy to understand. The articles we publish are increasingly accompanied by electronic supplementary materials such as high-quality images [3] and videos [4] that can be readily downloaded for educational use. These files are very frequently accessed by our readers.

- Critical care requires multidisciplinary expertise and relies on acquiring competence in the management of severe forms of all diseases. Expanding these skills, both at a professional and a qualitative level, is a clear aim of the journal. Moreover, critical care is also a very technical specialty, with a constant flow of new developments. All these aspects should be covered by the journal once they attain the required quality.

- Clinical studies of all designs are welcome. Large cohorts, multinational observational studies [5], randomised clinical trials [6], systematic reviews [7] and meta-analyses [8] have all been recently published in the journal, and some articles have been downloaded more than 70,000 times. ICM publishes all of critical care and welcomes contributions from the entire world. Experimental investigations and bench studies are for our sister journal ICMx. However, all studies that address a relevant clinical question and include critically ill patients of any age group are welcome.

- ICM adheres to the recommendations of the EQUATOR network. Submissions to the journal have to follow the guidelines for the study type concerned (CONSORT, STROBE, PRISMA, STARD and TRIPOD). Pre-registration of the statistical analysis plans in the public domain should follow the most recent

\section{勿 Springer}


Table 1 The hopes and ambitions of Intensive Care Medicine

1. To publish original, up-to-date articles reporting clinical research conducted to the highest possible ethical and methodological standards

2. To disseminate high-quality educational materials

3. To highlighting the multidisciplinary components of critical care

4. To welcome studies of all designs as long as they address a clinically relevant question and draw a reasonable conclusion

5. To publish all of critical care, from paediatrics to geriatrics

6. To maintain strict adherence to the Equator network guidelines

7. To continue providing a speedy yet careful review process

8. To be the place for multicentre and multinational studies

9. To promote knowledge transfer by new approaches to publication

10. To maintain the true interactions between editors, authors, reviewers and readers created by a highly responsive editorial board

guidelines. Particular attention to ethical issues is another important qualifying element of our editorial policy.

- ICM has an editorial process that is among the fastest in medical journals. The editors are committed to making timely and careful decisions. A panel of very talented and dedicated reviewers, including statisticians, guarantees an honest and valuable review process. An active board of 250 reviewers, along a group of $>10,000$ reviewers, provide prompt high-quality reviews.

- ICM hopes to be the place where critical care networks want to publish the results of their multicentre cohort studies [9] and trials. The increasing impact factor, the huge and still increasing number of downloads and ICM usage in general, and the worldwide coverage guarantee capillary dissemination throughout the critical care community.

- ICM is open for the development of new ways of writing and reading and new approaches to publication that favour knowledge transfer $[10,11]$. The journal's goal is to promote the development of new ideas and new insights in the field of critical illness.

- The journal has created true interactions between editors, authors, reviewers and readers. A highly responsive board welcomes feedback and controversies, not only by means of conventional correspondence, but also on the various platforms offered by social media.

Sharing these ten points with our readers, authors, reviewers and editors is also a good way to increase opportunities for further enhancement of the journal. We hope that ICM, the journal with the highest impact factor among those that publish only critical care, is well on the way to becoming the target journal for the dissemination of the best of the scientific activities in this continuously evolving field.

\begin{abstract}
Author details
1 School of Medicine and Surgery, University of Milan-Bicocca, Via Cadore 48, 20900 Monza, Italy. ${ }^{2}$ Department of Intensive Care, Section 4131, Copenhagen University Hospital, Copenhagen, Denmark. ${ }^{3}$ Medical Intensive Care Unit, AP-HP, Bichat University Hospital, Paris, France. ${ }^{4}$ University Paris Diderot, Sorbonne Paris Cité, Paris, France.
\end{abstract}

Received: 28 July 2016 Accepted: 29 July 2016

Published online: 6 August 2016

References

1. Suzumura EA, Amato MBP, Cavalcanti AB (2016) Understanding recruitment maneuvers. Intensive Care Med 42:908-911. doi:10.1007/ s00134-015-4025-5

2. Sharshar T, Citerio G, Andrews PJD et al (2014) Neurological examination of critically ill patients: a pragmatic approach. Report of an ESICM expert panel. Intensive Care Med 40:484-495. doi:10.1007/s00134-014-3214-y

3. Morimont P, Lambermont B, Gaspard V, Defraigne J-O (2015) Molding thrombus of an ECMO cannula floating in the right atrium. Intensive Care Med 41:1965-1966. doi:10.1007/s00134-015-3779-0

4. Via G, Tavazzi G, Price S (2016) Ten situations where inferior vena cava ultrasound may fail to accurately predict fluid responsiveness: a physiologically based point of view. Intensive Care Med 42:1164-1167. doi:10.1007/s00134-016-4357-9

5. Cecconi M, Hofer C, Teboul J-L et al (2015) Fluid challenges in intensive care: the FENICE study: a global inception cohort study. Intensive Care Med 41:1529-1537. doi:10.1007/s00134-015-3850-x

6. Debaty G, Maignan M, Savary D et al (2014) Impact of intra-arrest therapeutic hypothermia in outcomes of prehospital cardiac arrest: a randomized controlled trial. Intensive Care Med 40:1832-1842. doi:10.1007/ s00134-014-3519-x

7. Eskesen TG, Wetterslev M, Perner A (2016) Systematic review including re-analyses of 1148 individual data sets of central venous pressure as a predictor of fluid responsiveness. Intensive Care Med 42:324-332. doi:10.1007/s00134-015-4168-4

8. Angus DC, Barnato AE, Bell D et al (2015) A systematic review and meta-analysis of early goal-directed therapy for septic shock: the ARISE, ProCESS and ProMISe Investigators. Intensive Care Med 41:1549-1560. doi:10.1007/s00134-015-3822-1 
9. Rhodes A, Phillips G, Beale R et al (2015) The Surviving Sepsis Campaign bundles and outcome: results from the International Multicentre Prevalence Study on Sepsis (the IMPreSS study). Intensive Care Med 41:1620-1628. doi:10.1007/s00134-015-3906-y

10. Mayo P, Mekontso-Dessap A, Dessap AM, Vieillard-Baron A (2015) Myths about critical care echocardiography: the ten false beliefs that intensivists should understand. Intensive Care Med 41:1103-1106. doi:10.1007/ s00134-014-3622-z
11. Tattevin P, Durante-Mangoni E, Massaquoi M (2014) Does this patient have Ebola virus disease? Intensive Care Med 40:1738-1741. doi:10.1007/ s00134-014-3473-7 